\title{
The Theory of Structural Anomie and Law Breaking: Case of Ahvaz's Scientific Applied University (Iran)
}

\author{
Khedry Leila $^{1}$, Hosseyni Maryam ${ }^{2}$, Salehi Shablizi Massod ${ }^{3}$, Bani Naimeh Isa $^{4}$, \\ Moshtaghi Ali ${ }^{5}$ \\ ${ }^{1}$ Hamedan Branch, Islamic Azad University Science and Art Research Campus, Hamedan, Iran \\ ${ }^{2}$ Farhangian University, Ahvaz Branch, Iran \\ ${ }^{3}$ Islamic Azad University, Abadan Branch, Iran \\ ${ }^{4}$ Islamic Azad University, Shushtrar Branch, Iran \\ ${ }^{5}$ Hamedan Branch, Islamic Azad University Science and Art Research Campus, Hamedan, Iran
}

\section{Abstract}

This study aimed to explain law breaking with applying structural theory of anomy. To do this, relationship between individuals, achievement orientation, universalism and money fetishism as four indexes of cultural successfulness, with law breaking from one side, and relationship between socioeconomic status(SES) from two objective and subjective dimensions with law breaking as well as structural anomy and its components were examined. The applied method was survey and 400 people were selected randomly among the students. The questionnaires which used in the study included three instruments: structural anomy scale, socio- economic status questionnaire, and law breaking tendency questionnaire. A positive significant relationship between structural anomy and law breaking was found. Results showed that the effect of individuals and money fetishism on law breaking is significant; however the effect was not appeared for achievement orientation and universalism. No significant relationship was found between law breaking and SES. The achieved relationship between objective SES and structural anomy was positive but weak. In sum, it can be said that the theory can explain law breaking phenomena properly.
Keywords

structural anomie; lawvidence; scientific-applied Uhiversity of Ahvaz

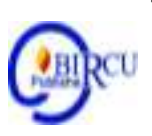

\section{Introduction}

Law breaking is a contagious problem which is common among many people. The tendency is a social problem which threats order and social organization. Law breaking in Iran always has been an important issue; in effect legality of law makers and following the laws by people are two problems in Iran. The Law breaking problem in underdeveloped countries is severe.

Transition from tradition society to a modern one, facing with imported phenomena and technologies, unstable political situation, foreign threats and fiscal crisis, make people law breakers. In the situation which can be called anomic in terms of Durkheim [4] people follow their personal interests and every instrument can be used to attain the purposes as the people in an anomic situation haven't empathy towards others. One of the main reasons of law breaking in the society is lack of regulating power of norms on behaviors of people. If the behaviors and their related aspirations are uncontrollable, there will be unfulfilled needs which continue forever. According to Durkheim, this is not the human nature which determines the 
changeable realm of our needs. Accordingly, some of the most important roots of law breaking among people are uncontrollable aspirations as well as over emphasizing on fiscal successfulness.

Two theories of Durkheim and Messner and Rosenfeld are the best in terms of fiscal explanation of crime and delinquency. The latest version of anomy theory has been formulated by Messner and Rosenfeld. There is a higher level explanation of anomy theory which is called Institutional Anomie Theory (IAT). This theory counts antisocial behaviors as a function of cultural as well as institutional effects. A distinctive characteristic of theory from other types of anomic theories, is studying culture and social structure with respect to their representation in social institutions. As other anomie theories, IAT relies on Durkheimian bases which say normal levels of community's activities and its criminal forms reflect critical characteristics of the community's institution. IAT accepts Parsons' conceptualization of institutions. Parsons distincts between subjective and objective approaches towards studying social institutions. The first one focuses on understanding behaviors in personal level, however the latter relates to examine institutional order in the society. Parsons proposes that each society has a system of values which is common, significant for its members.

When the system faces with severe instability and disorder, all people are engaged in fighting against each other through it. For Parsons shared value system is a basis which social institutions relied on it. Massner and Rosenfeld funded their theory with using Parsons and anomie theories. According to Massner and Rosenfeld crime is committed in societies which its institutions' equality disturbs and economical values enter to other institutions. They believe that anomie is developed due to weakness in institutions like family and education which should control over insisting on fiscal successfulness; instead they convey the values. In the societies with domination of fiscal institution, getting to successfulness is encouraged by cultural values, anyhow. Four cultural values which are focused by the society consisted of achievement orientation, individualism, universalism and money fetishism. The first construct refers to aspiration successfulness. This is a criterion which everybody is assessed by it. In fact does not matter how, but being winner is important. Individualism refers to a cultural pressure that forces people to be successful just by themselves. There is also a situation which asks all people regardless of their race, ethnicity or gender to be successful; it is cited as universalism. According to the rule similar values and purposes should be achieved by all people. As it was cited the responsible institutions for perverting from economy dominance, family and education are weak. The weakness is ascribed to three reasons : 1) devaluation of non fiscal functions and roles, 2) when there is a conflict, non fiscal roles changes into subordinate's fiscal ones, and 3) language standards and norms of fiscal field insert into non fiscal realms, e.g. father sees himself as home's manager, as if he works at office not living there.

\section{Review of Literature}

Bjerrgard and Cochran tested IAT with applying the second order data. The data was collected as indexes of insufficiency of non fiscal institutions of the society. Their results confirmed main premises of the theory, i.e. with weakness in the institutions, the crime's rate is going up. Chamlin and Cochran examined the proposal that the effect of economy on the rate of crime depends on non fiscal institutions. They used economical crime's rate to test the proposition. The percentage of underlined poverty population counted as the index of economical situation, divorce rate and dissociated families are viewed as index of family's power, membership and going to church as an index of religion institution and percentage of 
people in voting age range and people who vote viewed as an index of political institution. The result showed that whenever deficiency in non fiscal institutions is increased poverty effect on crime is raised. Massner and Rosenfeld tested the effect of merchandising and market labours on the rate of homicide between miscellaneous nations. With controlling demographical as well as socio economic variables they found that the nations with higher scores in unmerchandising, have lower rate of homicide. In only one study about institutional anomie at personal level, Muftic, studied the student's tendency to cheating. Results showed that with rising in institutional anomie, the tendency is rising up too.

\section{Research Methods}

\subsection{Population and Sampling}

Statistical Population In the study is all students of scientific-applied University .with applying Cohen formula [15] and adding 20\% as attrition rate 415 People were selected, finally 400 people remained in the study. Among them there were 191 male and 209 female.

\subsection{Instrumentation}

There were totally four tests in the study, institutional anomic scale, socio- economic status scale (objective), the subjective version of the test, and law breaking scale. In the following, the scale will be described in details.

\subsection{Institutional Anomie Scale}

The scale was made by Muftic [12]. There are four dimensions of individualism, achievement orientation, universalism and money fetishism; the items have five, five, two and three items respectively. Respondents could answer to the items on a five options continuum, from completely agree to completely disagree. The validity of the scale and its subscales were as $.79, .67, .15, .65$ and .66 for the whole score, individualism, achievement orientation, universalism and money fetishism respectively.

\subsection{Objective Ses Scale}

The scale refers to the objective position of people in the society in terms of economical class and inequality in wealth distribution [16]. The items in the scale focused on the income of family and finally sum of the all scores makes an index which in turn is called Objective SES scale.

\subsection{Subjective Ses Scale}

The scale is based on subjective assessment of people from themselves. There are 6 items in the scale which should be answered on a 5 options based. Its validity was .71 in the current study and .69 in another study.

\subsection{Law Breaking Scale}

There were 6 items in the scale which covered deviant and criminal behaviours; its validity and reliability coefficients with applying professionals decision making and Guttmann method were .87 .92 respectively. 


\section{Discussion}

The average of respondents' age was 21.9. Among them 298 lived in urban areas and the rest were in the rural places. The race distribution among the group was Turk 37 , Kurd 77 , Lore109, Arab64 and Fars 113 people. It was found that all dimensions of ITA showed positive, significant correlation with law breaking; the coefficients were .183, .137,.157, .169 and .118 for individualism, achievement orientation, universalism, money fetishism and whole score respectively. No significant relationship was found between SES and law breaking. A mild relationship was found between achievement orientation and objective SES, $\mathrm{r}=.102$. Stepwise method of regression showed that individualism and money fetishism had the highest effect in explaining the law breaking variance, $\mathrm{R}=.141$ and , $\mathrm{R}=.12$ respectively. To compare male and female in terms of law breaking, a t.test was administered $t=2.77$, $\mathrm{p}=.006, \mathrm{df}=398$ which was significant. The statistics, $\mathrm{t}$-test, also was applied to test difference between rural and urban areas, $\mathrm{t}=2.08, \mathrm{p}=.03, \mathrm{df}=398$; a significant effect. No significant difference was found between the group in terms of ethnicity, $\mathrm{t}=1.09, \mathrm{p}=.358, \mathrm{df}=4$.

The study aimed to test IAT as the latest version of the anomie theory among Iranian students. Results showed significant effect of institutional anomie's law breaking, the effects specifically was observed for individualism and money fetishism. This finding implies that insisting on successfulness can be valuable; however it has some unwanted side effects. With personal achievement and being successful without others help, another face of anomic function of Durkheim will be appear which through it uncontrolled aspirations should be fulfilled any way. Fiscal achievement as the main criterion of successfulness can derives people towards the statement that purpose can fulfil the instrument. In an anomic society, people should make money and this is an endless dream. In the society all institutions, family, school, office and so on try to make human successful in this regard. This study also showed that law breaking at least among students has not classical distribution. The finding is not congruent with Merton theory which says people from low SES tend to be more engaged in law breaking activities.

\section{Conclusion}

There were two findings, positive relationship between objective SES and achievement orientation as well as the first one with ITA. The finding is in line with Rodman (Rodman, 1963: 212) which says people from low SES like successfulness and achievement orientation, but to be adapted with deprivation, seek low levels of successfulness. There was also found that ethnicity is not a predicator for law breaking.

\section{Acknowledgments}

Researchers in the study wish to thanks the head and staff of the scientific-applied University for their Friendly treating during the study.

\section{References}

Kalantari,S, Rabani,R , Sedaghet, K.( 2006). The relationship between poverty and law breaking, Social Welfare Quarterly, ,18, 130-142.

Rezaie, M. (2005).The effective elements on law breaking, Journal of Sociology of Iran. 6,3, 47- 69 .

Rafipoor, F. (1989). Anomie, 2nd ed. daneshgaran publication, Tehran, iran.

Gianfranco, P, Durkheim, Oxford: Oxford University Press, United Kingdom, 2000. 
Rosenfeld, R., \& Messner, S. F. (1995). Crime and the American dream: An institutional analysis. The legacy of anomie theory, 159-182.

Siegl, L, Criminology,1st ed., West Wadsworth Publishing Company, MR, USA, 1998.

Mayhew, L, Talcott Parsons: On institutions and social evolution. University of Chicago Press. USA, 1982.

Messner,S, , Helmut,T, Rosenfeld,R, (2008).Institutions, Anomie, and Violent Crime: Clarifying and Elaborating Institutional-Anomie Theory, International Journal of Conflict and Violence, , 2, $163-181$.

Bernburg, J. G. (2002). Anomie, Social Change and Crime. A Theoretical Examination of Institutional-Anomie Theory. British Journal of Criminology,42(4), 729-742.

Savolainen, J, Inequality, Welfare State and Homicide: Further Support for the Institutional Anomie Theory, Criminology, 2000, 38, 1021-1042.

Rosenfeld, R, Steven, F, M, The Origins, Nature and Prospects of Institutional-Anomie Theory, In The Essential Criminology 2nd ed. S. Henry and M. M. Boulder, CO: Westview Press, NJ, USA, 2006, pp. 164-173.

Muftic, L, Advancing Institutional Anomie Theory: A Microlevel Examination Connecting Culture, Institutions, and Deviance, International Journal of Offender Therapy and Comparative Criminology, 2006, 50,6, 630-653.

Bjerregaard, B ; Cochran, J, Want amid plenty: Developing and testing a cross-national measure of anomie, International Journal of Conflict and Violence, 2008,2, 182-193.

Chamlin, M, Cochran, J, Assessing Messner And Rosenfeld Institutional Anomie Theory: A Partial Test, Criminology, 1995, 33,411-29.

Cohen, J, Statistical Power Analysis for the Behavioural Sciences, 2nd ed., Hillsdale, NJ: Erlbaum.USA, 1988.

Ritzer, G, Encyclopaedia of Social Theory, 3rd ed., Thousand Oaks, CA: Sage, Canada, 2004.

Nabavi,A, Hosseynzadeh,A,H, Hosseyni,H, Study of effecting of social and economic factors on societal security feeling, Sociological Studies, 2011,21, 73-96.

Rodman, H, The Lower Class Value Stretch, Social Forces, 1963, 42, 205-215. 